\title{
Modal Analysis of Automobile Brake Drum Based on ANSYS Workbench
}

\author{
Dan Yang ${ }^{1,2}$,Zhen $\mathrm{Yu}^{1,2}$, Leilei Zhang ${ }^{1,{ }^{*}}{ }^{*}$ and Wentao Cheng ${ }^{2}$ \\ ${ }^{1}$ Key Laboratory of Metallurgical Equipment and Control Technology, Ministry of Education, Wuhan \\ University of Science and Technology, Wuhan 430081, China. \\ ${ }^{2}$ Hubei Key Laboratory of Mechanical Transmission and Manufacturing Engineering, Wuhan University of \\ Science and Technology, Wuhan 430081, China. \\ a380530828@qq.com \\ * please mark the corresponding author with an asterisk
}

Keywords: Brake drum; Modal analysis; Finite element

\begin{abstract}
The dynamic characteristics of the brake drum are theoretically calculated and studied by the finite element method. The finite element model of the brake drum is established by using ANSYS software. Through the analysis and calculation of the model, the first 12 natural frequencies and vibration shapes are computed, which provides a reference for analysis and design of the brake drum.
\end{abstract}

\section{Introduction}

The automobile brake is the main working device of the automobile braking system. Its strength, stiffness and dynamic characteristics directly affect the working characteristics and service life of the braking system, and vehicle safety, comfort, handling stability, noise and other basic properties [1]. With the increasing number of cars in the market, designers pay more and more attention to the research of automobile brakes. Brake drum with high strength heat dissipation is the key component of brake system of automobile and engineering machinery, which is mainly used for forced braking [2]. The basic requirements of automobile brake drum include: sufficient mechanical properties, good heat dissipation performance and thermal fatigue characteristics, good wear resistance, uniform organization and good shock absorption [3]. Although the structure of brake drum is relatively simple, it is an important component to ensure the safety of the car. Common failure patterns of the Brake drum are: cracking and excessive wear. When abnormal wear and vehicle braking occur, the friction produces a lot of heat, a large amount of heat is generated by friction, resulting in the excessive temperature of brake drum and friction plate is too high, leading to the decrease of friction coefficient and the influence of braking effect [4]. With the rapid development of the national economy and the continuous improvement of road conditions, traffic density is increasing day by day, the occurrence of traffic accidents constantly warning the importance of braking system.

In order to improve the braking efficiency and stability of the automobile braking system, it is of great value to carry out modal analysis of the braking system. Previous literatures mainly studied the design, optimization and finite element analysis of the brake drum related functional components, but the modal analysis of the brake drum was rarely studied. However, the modal analysis of the brake drum plays an important role. Through the modal analysis, the natural frequencies and vibration characteristics of the brake drum can be obtained. Theoretical basis for the study of vibration and noise of brake can be provided through the modal analysis, so as to improve the strength of brake drum, the heat dissipation condition and the braking safety. Therefore, in this paper, the structural modal analysis of a certain type of brake drum is carried out, and its structural size is optimized to provide reference for design and manufacture [5].

\section{Structure and Parameters of Drum Brake}

Typical drum brakes mainly consist of three parts: brake drum, brake shoe (collar and hoof) and friction lining, as shown in Figure 1. The corresponding material properties are shown in Table 1. The braking 
process is that the collar and the shoe rotate outwards from the axis of the supporting eccentric shaft under the hydraulic pressure of the wheel cylinder, so that the friction pad is contacted with the brake drum to produce friction, so as to realize the braking function [6]. If the brake drum, brake shoe and friction lining are considered as a whole, the brake is only subjected to the braking force of the outer wheel as the wheel cylinder. The location of the boundary condition can be represented by the hinged rotation of the brake shoe around the support.

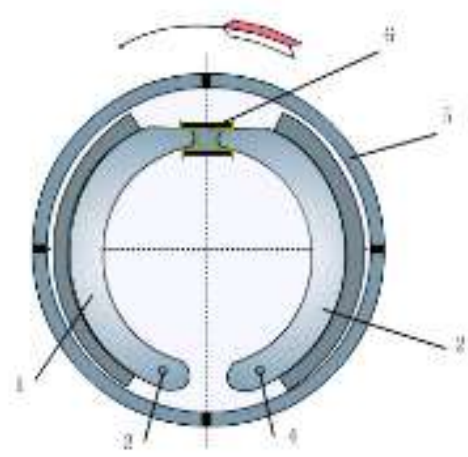

Figure 1. Finite Structure of collar and hoof brake

1: Leading shoe; 2: Trailing shoe; 3.4: Fulcrum; 5: Brake drum; 6: Brake wheel cylinder.

Table 1 Material characteristic parameters

\begin{tabular}{c|c|c|c}
\hline & Elastic modulus/Gpa & Poisson ratio & Density $/ \mathrm{kg}^{-3}$ \\
\hline Brake drum & 120 & 0.25 & 7500 \\
\hline Brake shoe & 189 & 0.3 & 7900 \\
\hline Friction lining & 0.37 & 0.25 & 3600 \\
\hline
\end{tabular}

\section{Modal Analysis and Optimization of Brake Drum}

Model Establishment and Simplification of Drum Brake. In the modeling process, in order to avoid errors and improve the meshing and calculation speed of finite element calculation, the brake drum entity model was simplified, some subtle structural features should be deleted, such as holes and screw holes, and observer the following principles [5]:

a. The nonlinear taper cone structure in entity structure such as bradawl and conical surface are simplified into a cone or line. Avoid generating gaps when generating meshes, leading to the failure to build finite element models;

b. The relatively complex geometry of the solid model is treated as a simple geometric shape, such as turning the fillet to a right angle;

c. Geometric features, such as thread holes and tool grooves, which have little effect on the analysis results and calculation accuracy, are neglected. Finally, a simplified 3D solid model of the brake drum is shown in figure 2. 




Figure 2. Finite Simplified 3D model of brake drum

Mesh Generation. Mesh generation is an important step in the pre-processing of finite element method, and it is time-consuming. The correct and reasonable meshing is the key to numerical simulation of finite element method. The quality of the mesh will directly determine the speed, accuracy and accuracy of the final analysis. This step plays a global role in the validity and reliability of the finite element analysis. When the brake drum is meshed, the 3D entity Solid 187 tetrahedron element is selected, and each unit has 10 nodes. The brake drum is meshed by the free meshing method. The mesh diagram of the finite element model is shown in Figure 3, and the brake drum is divided into 20944 nodes and 11751 units.

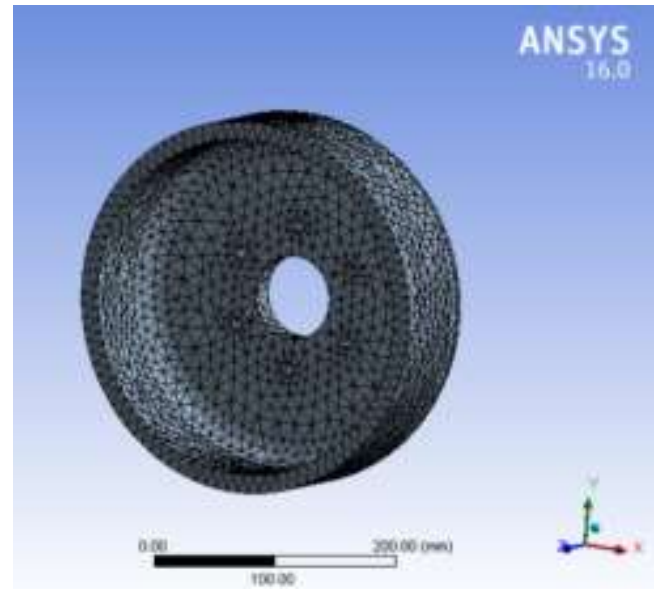

Figure 3. Finite Mesh generation of brake drum

Adding Constraints and Solving Calculations. The brake drum modal test can get natural frequency of brake drum under free condition, and the brake drum is usually connected with other parts, so the displacement constraints in the bolt hole of cylinder brake drum and other parts connected on both axial and normal. Because the external excitation frequency of the brake drum is low, the low order vibration mode plays a decisive role in the dynamic performance of the brake drum. Therefore, the first 10 natural frequencies and vibration modes of the brake drum are solved by Block Lanczos method. The advantage of the method is that the mesh quality is low and the running speed is fast.

\section{Calculation Results and Analysis}

The modal analysis of the brake drum is carried out, and the 1 10 order natural frequencies and modes of the free modal analysis are solved. The calculated results of natural frequencies are shown in Table 2. Figure 4 shows the 1, 3, 5, 6, 9 order vibration modes of the brake drum. 
Table 2 element analysis value of natural frequency of brake drum

Tabular Data
\begin{tabular}{|l|l|l|}
\hline & Mode & - Frequency [Hz] \\
\hline 1 & 1. & 713.47 \\
\hline 2 & 2. & 713.65 \\
\hline 3 & 3. & 842.38 \\
\hline 4 & 4. & 842.39 \\
\hline 5 & 5. & 1047.2 \\
\hline 6 & 6. & 1690.2 \\
\hline 7 & 7. & 1691.9 \\
\hline 8 & 8. & 1981.3 \\
\hline 9 & 9. & 2653.9 \\
\hline 10 & 10. & 2654.5 \\
\hline
\end{tabular}

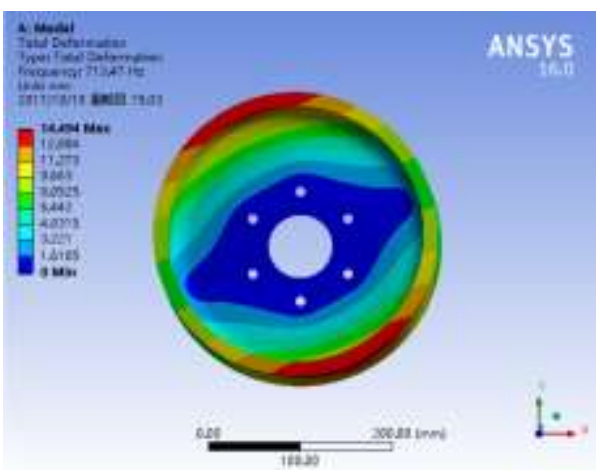

a. 1 order vibration mode diagram

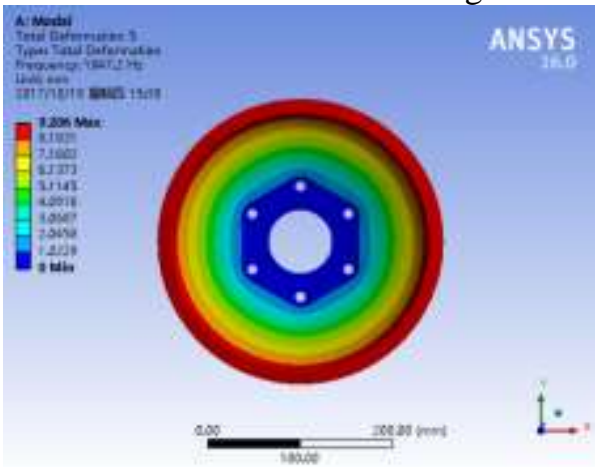

c. 5 order vibration mode diagram

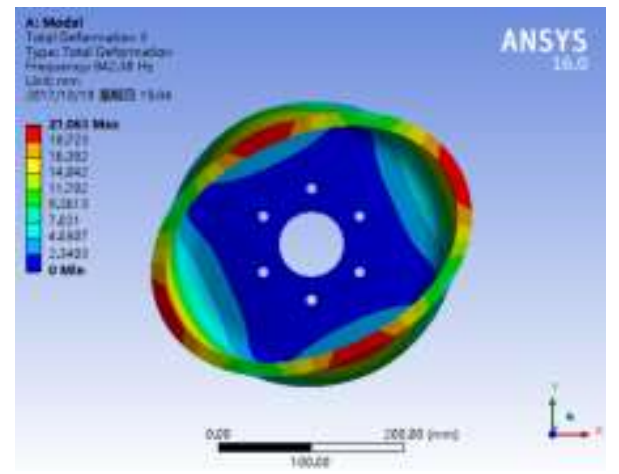

b. 3 order vibration mode diagram

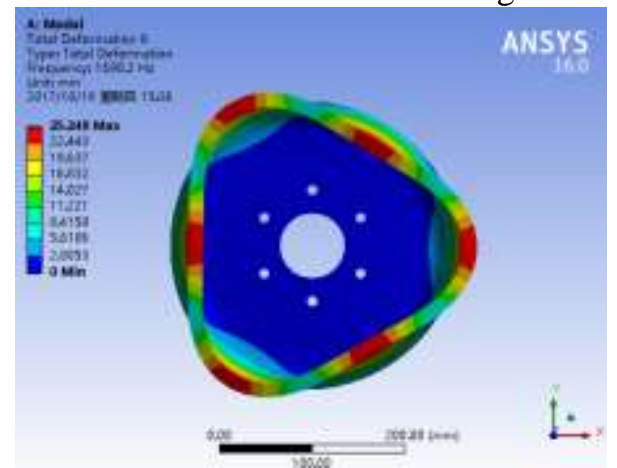

d. 6 order vibration mode diagram



e. 9 order vibration mode diagram

Figure 4. Finite Modal diagram of natural frequency of brake drum

According to the calculation results, the main vibration mode of the first, second order brake drum is that the brake drum edge has two deformations along the radial direction, and the shapes are elliptical; the deformation of the brake drum edge of the fifth, eighth order main vibration mode is basically equal; The brake drum edge of the third, fourth order main vibration mode has the biggest deformation along the radial direction, and the shape is elliptical. The main vibration mode of the sixth, seventh order is similar, 
and the deformation at the edge is the same, showing an obvious triangle, which is easy to cause the wear degree of the friction liner to be greatly different. The vibration displacement at the edge of the brake drum of the ninth, tenth order main vibration mode is larger, which is easy to produce vibration and noise and accelerate the wear of the friction lining.

\section{Conclusion}

Noise pollution is one of the major hazards in today's society, and braking noise is an important part of traffic noise. The main components of drum brake: brake floor, brake drum, brake shoe and friction lining are often used as the main vibration source of brake noise [6]. It has been shown that vibration and noise are closely related to the interaction between brake drum, brake shoe and brake floor [7].

According to the structure and mechanical performance requirements of drum brake, the brake drum is analyzed and calculated on the basis of finite element method. The natural frequencies and vibration modes of the brake drum are obtained, and the modal analysis of the calculated results is carried out. The third order natural frequency of the brake drum is $834.64 \mathrm{~Hz}$, while the $500 \sim 1000 \mathrm{~Hz}$ is the main research area of brake noise. The natural frequency is related to the quality and strength of the parts. The strength is higher, the quality is lighter, and the natural frequency is greater. Through the analysis of the natural frequency of the brake drum, and the influence of the structural change on the natural frequency, it is beneficial to the design of the brake drum. In order to change the dynamic response of the brake drum, the material parameters of the brake drum, the quantity of the tendon and the mass of the brake drum should be changed. Therefore, the finite element modal analysis can provide a reference for the design of brake drum and the selection of working parameters, so that the structure of the designed parts is more reasonable.

\section{Acknowledgement}

The work is supported financially by the Natural Science Foundation of Hubei province under Grants (No.2016CFB581) and the research project of Hubei Education under Grants(No.Q20151103).

\section{References}

[1] J.X. Yue, J.X. Wan and B.W. Dong: Equipment Manufacturing Technology, 2016.

[2] Y. Zhao, L.Q. Ren, and X. Tong: Journal of Bionic Engineering, Vol. 5 (2008) No.9, p.20.

[3] H. Lee, H.S. Yoon: Journal of Mechanical Science and Technology, Vol. 31(2017) No.7, p.3211.

[4] B. Ali, M. Bouchetara: Applied Thermal Engineering, Vol. 32(2012), No.1,p.59.

[5] K. Liu, M. Peng and Y.Q. Lin: Journal of Guangdong University of Technology, Vol. 30(2013) No.1, p.92.

[6] H.W. Li, H.W. Dong and H.L. Du: Forestry Machinery and Woodworking Equipment, 2011.

[7] S. Wang: Drive System Technique, 2016. 